\section{Vacinação contra rubéola em mulheres em idade reprodutiva no Município de Campinas, São Paulo, Brasil}

\author{
Rubella vaccination in women of childbearing age \\ in Campinas, São Paulo State, Brazil
}
Vacunación contra la rubeola de mujeres en edad reproductiva en el municipio de Campinas, São Paulo, Brasil

\author{
São Paulo, Brasil
}

Priscila Maria Stolses Bergamo Francisco 1 Caroline Senicato 1

Maria Rita Donalisio 1

Marilisa Berti de Azevedo Barros 1

\footnotetext{
${ }^{1}$ Faculdade de Ciências Médicas, Universidade Estadual de Campinas, Campinas, Brasil.

Correspondência P. M. S. B. Francisco Departamento de Saúde Coletiva, Faculdade de Ciências Médicas, Universidade Estadual de Campinas.

Rua Tessália Vieira de Camargo 126, Campinas, $S P$ 13083-887, Brasil. primaria@fcm.unicamp.br
}

\begin{abstract}
Women of reproductive age are the population of greatest interest for the prevention of congenital rubella syndrome. The aim of this study was to evaluate the prevalence of rubella vaccination in women and to identify factors associated and motives for non-adherence. A cross-sectional population-based study, in Campinas, São Paulo State, Brazil, in 2008/2009, was carried out with stratified random, two-stage cluster sampling. Of the 778 women aged 10 to 49 years, 83.8\% (95\%CI: 79.6-88.0) reported vaccination in life. Age group (20-39 years), per capita household income greater than 3 times the minimum wage and orientation of health care professionals about the vaccine, were positively associated with rubella vaccination. The main motives for non-adherence were lack of orientation of professionals about their importance (48.5\%) and not consider it necessary (18.9\%). The recommendation of professionals was the factor most strongly associated with women's adherence to vaccination. In this sense, an indication of vaccination by health care teams can increase the knowledge about the importance their and benefits.
\end{abstract}

Congenital Rubella Syndrome; Rubella Vaccine; Vaccination; Women's Health

\section{Resumo}

As mulheres em idade reprodutiva são a população de maior interesse para a prevenção da síndrome da rubéola congênita. O objetivo do trabalho foi avaliar a prevalência de vacinação contra rubéola em mulheres e identificar fatores associados e motivos da não adesão. Tratase de estudo transversal de base populacional, realizado em Campinas, São Paulo, Brasil, em 2008/2009, com amostra por conglomerados e em dois estágios. Das 778 mulheres de 10 a 49 anos, 83,8\% (IC95\%: 79,6-88,0) referiram vacinação em algum momento da vida. Faixa etária (30-39 anos), renda familiar per capita superior a três salários mínimos e a orientação de profissional de saúde estiveram positivamente associadas à vacinação contra a rubéola. Os principais motivos da não adesão foram a falta de orientação do profissional de saúde sobre sua importância (48,5\%) e não considerá-la necessária (18,9\%). A recomendação do profissional de saúde foi o fator mais fortemente associado à adesão das mulheres à vacinação. Nesse sentido, sua indicação pelas equipes de saúde pode ampliar o conhecimento sobre sua importância e seus benefícios.

Síndrome da Rubéola Congênita; Vacina contra Rubéola; Vacinação; Saúde da Mulher 


\section{Introdução}

A rubéola é uma infecção aguda exantemática, de etiologia viral, que apresenta alta transmissibilidade, cuja importância epidemiológica está relacionada à síndrome da rubéola congênita. A transmissão do vírus por via transplacentária pode levar à infecção do feto, comumente relacionada ao aborto, natimortalidade, malformações congênitas como cardiopatias e surdez neurosensorial, além de afecções oftalmológicas e meningoencefalite 1,2,3.

Os custos diretos e indiretos da síndrome da rubéola congênita são elevados devido à cronicidade, gravidade das manifestações e impactos psicológico e social que provocam nas famílias e nos pacientes $3,4,5$.

A rubéola e a síndrome da rubéola congênita integram a lista de doenças de notificação compulsória no Brasil, desde 1996. No ano de 1997, foram notificados 32.825 casos de rubéola dos quais $65,3 \%$ na Região Sudeste. Nos anos seguintes, foram identificados surtos de rubéola em vários estados. Como resultado de ações governamentais de vigilância e controle da doença, a partir de 2002 houve um decréscimo da incidência de rubéola no país, chegando a 233 casos, em 2005. Contudo, em 2006, houve um incremento de casos confirmados (1.317) e surtos nos estados do Rio de Janeiro, Minas Gerais, Ceará e São Paulo. Em 2007, o número de doentes chegou a 8.753, 93\% confirmados por critério laboratorial 6 . Dentre os casos desse ano, 161 gestantes foram infectadas pelo vírus 7, resultando em 29 casos de síndrome da rubéola congênita no país. Após campanha de vacinação e vigilância epidemiológica intensificada em 2008, observou-se uma queda no número de casos confirmados de rubéola (1.854 casos), mas aumento dos casos registrados de síndrome da rubéola congênita, atingindo 48 recém-nascidos. Em 2009, caiu para 15 o número de casos registrados de síndrome da rubéola congênita no Brasil 6 (Departamento de Informática do SUS. Síndrome da rubéola congênita: casos confirmados ou compatíveis notificados no SINAN Net. http://dtr2004.saude.gov. $\mathrm{br} /$ sinanweb/tabnet/dh?sinannet/src/bases/ srubeolacbrnet.def, acessado em 17/Ago/2012).

Com caráter endêmico, antes da introdução da vacina nos programas de imunização no Brasil, os surtos de rubéola ocorriam a cada 3 a 6 anos 7. Sendo a rubéola uma doença imunoprevenível, a vacinação de baixo custo e com efetividade de $97 \%$ é a medida indicada para o controle, eliminação ou erradicação da rubéola e da síndrome da rubéola congênita 3 .

No final do século XX, a Organização PanAmericana da Saúde (OPAS) propôs o controle da rubéola e prevenção da síndrome da rubéola congênita nas Américas, definindo a meta de eliminação da rubéola e da síndrome da rubéola congênita nas Américas até $2010^{3,8}$. As principais recomendações foram a introdução da vacina contra a rubéola na rotina aos 12 meses, campanhas em massa entre adolescentes e adultos (speedup) e seguimentos periódicos de menores de cinco anos para avaliar a cobertura, além de reforçar a vigilância da doença e da síndrome da rubéola congênita 9 .

No Brasil, a vacina tríplice viral contra sarampo, caxumba e rubéola foi gradualmente implantada nas Unidades Federativas, iniciando-se no Estado de São Paulo em 1992. No ano seguinte, foi disponibilizada para o Distrito Federal e, em 1995, para o Paraná e o Espírito Santo. Em 1996, a vacina foi também implantada em Santa Catarina, Rio de Janeiro e Minas Gerais e, em 1998, foi estendida para as mulheres em idade fértil, sendo ofertada nos anos seguintes nos demais estados também para esta faixa etária 10 . Somente em 2000, após a sua introdução no restante do país na forma de campanhas, é que a vacina tríplice viral passou a fazer parte do calendário nacional de imunização, inicialmente como dose de reforço para sarampo aos 15 meses, e posteriormente aos 12 meses e aos quatro anos de idade 12 (Portal da Saúde. Calendário básico de vacinação da criança. http://portal. saude.gov.br/portal/saude/visualizar_texto. cfm?idtxt=21462, acessado em 17/Ago/2012). Diante da meta de eliminação da rubéola e da síndrome da rubéola congênita no país, em 2001, as mulheres em idade reprodutiva passaram a ser alvo das campanhas de imunização contra rubéola (Campanhas de 2001 e 2002), incorporadas as recomendações da Organização Mundial da Saúde (OMS) 11,12. No entanto, apesar da diminuição da incidência entre as mulheres, observou-se o aumento da incidência no sexo masculino, o que norteou a realização da Campanha Nacional de Vacinação contra Rubéola de 2008, ampliando a população-alvo para homens e mulheres de 12 a 39 anos 11 .

De acordo com as informações de saúde disponíveis no banco de dados do Departamento de Informática do SUS (DATASUS. http://tab net.datasus.gov.br/cgi/tabcgi.exe?pni/cnv/cp nisp.def, acessado em 19/Jun/2012), em 2010 a cobertura da vacina tríplice viral atingiu 99,6\% e 94,9\% das crianças no Brasil e no Estado de São Paulo, respectivamente, e não foi registrado nenhum caso de síndrome da rubéola congênita no país a partir desse ano (DATASUS. http://dtr2004. saude.gov.br/sinanweb/tabnet/dh?sinannet/ src/bases/srubeolacbrnet.def, acessado em 17/ Ago/2012). Mesmo diante da crescente cober- 
tura, recomenda-se manter o programa de rotina com níveis de cobertura mínimos de $95 \%$, oferecer uma segunda oportunidade de vacinação por meio de campanhas para controlar e reduzir o acúmulo de suscetíveis e prevenir os casos importados, monitorar continuamente as recomendações preconizadas e os indicadores de vigilância da síndrome da rubéola congênita, além de detectar e responder rapidamente aos surtos valendo-se de estratégias de contenção 9 .

Grandes esforços são despendidos na vacinação de rotina e em campanhas na tentativa de estender essas coberturas, porém pouco se sabe sobre os motivos da não vacinação. Por meio do conhecimento dos fatores associados à adesão à vacina, pode-se identificar grupos específicos para direcionar estratégias efetivas 13 a fim de alcançar a eliminação da síndrome da rubéola congênita.

Não foi encontrado estudo nacional, de base populacional, sobre a prevalência de vacinação contra rubéola em mulheres na faixa etária reprodutiva, relevante parâmetro para avaliar os esforços de eliminação da doença.

O presente trabalho tem como objetivo estimar a cobertura de vacinação contra rubéola e verificar os fatores associados à vacinação em mulheres em idade reprodutiva (10 a 49 anos) residentes em Campinas, no ano de 2008, bem como identificar os motivos da não adesão à imunização.

\section{Métodos}

Trata-se de um estudo transversal de base populacional, que utilizou os dados do Inquérito de Saúde do Município de Campinas - ISA-Camp 2008/2009, realizado pelo Centro Colaborador em Análise de Situação de Saúde do Departamento de Saúde Coletiva da Universidade Estadual de Campinas (UNICAMP).

A pesquisa visou obter informações sobre três domínios de idade: adolescentes (10 a 19 anos), adultos (20 a 59) e idosos (60 anos ou mais). O tamanho da amostra foi definido considerando a estimativa de uma proporção de 0,50, com um erro máximo de 4 a 5 pontos percentuais, intervalo de $95 \%$ de confiança (IC95\%) e efeito de delineamento de 2, resultando em 1.000 indivíduos para cada domínio de idade. Esperando 80\% de taxa de resposta, o tamanho da amostra foi corrigido para 1.250 indivíduos em cada domínio.

O processo de amostragem do inquérito envolveu dois estágios: setores censitários e domicílios. No primeiro estágio, foram sorteados 50 setores censitários da área urbana do Município de Campinas com probabilidade proporcional ao número de domicílios. Realizou-se um sorteio sistemático, no qual os setores foram previamente ordenados pelo percentual de chefes de família com nível universitário. No segundo, foram sorteados os domicílios dos setores selecionados. Para cada um dos domínios de idade, foram sorteadas amostras independentes de domicílios. Com base na probabilidade dos moradores de cada grupo etário residir no domicílio, conforme dados do Censo Demográfico de 2000 (Instituto Brasileiro de Geografia e Estatística; http://www. ibge.gov.br), foram sorteados 2.150, 700 e 3.900 domicílios, respectivamente, para entrevistas com adolescentes, adultos e idosos. Nos domicílios sorteados foram entrevistados todos os residentes (os detalhes do plano de amostragem do inquérito ISA-Camp encontram-se disponíveis em: http://www.fcm.unicamp.br/centros/ccas/ arquivos/plano_de_amostragem.pdf, acessado em 03/Mai/2012).

Informações demográficas, socioeconômicas, de condições de saúde, de comportamentos relacionados à saúde e de uso de serviços de saúde foram obtidas junto ao entrevistado por meio de um questionário estruturado, previamente testado, aplicado por entrevistadores treinados e supervisionados (o questionário completo usado no inquérito está disponível para consulta em: http://www.fcm.unicamp.br/centros/ccas/ questionario_versao_final.pdf, acessado em 03/ Mai/2012).

Neste estudo foram analisadas as variáveis referentes aos registros de mulheres com idades entre 10 e 49 anos, sendo a variável dependente a vacinação contra rubéola em algum momento da vida (sim ou não). Já os motivos da não adesão à imunização foram obtidos pela seguinte pergunta: "Por que não tomou vacina contra rubéola?".

Para a análise dos fatores associados à vacinação, as seguintes variáveis independentes foram selecionadas, incluindo no modelo apenas as informações válidas:

Demográficas e socioeconômicas: idade, situação conjugal, cor da pele/raça (autorreferida), escolaridade, número de filhos, renda familiar mensal per capita (calculada em números de salários mínimos) e realização de atividade ocupacional remunerada.

Comportamentos relacionados à saúde: tabagismo, prática de atividade física no contexto de lazer e índice de massa corporal (IMC $=\mathrm{kg}$ / $\mathrm{m}^{2}$ ), calculado com peso e altura referidos.

Condições de saúde e morbidades: presença de doença crônica com diagnóstico médico ou de outro profissional de saúde, morbidade referida nas últimas duas semanas e hipertensão arterial.

Uso de serviços de saúde: procura de serviços de saúde nas últimas duas semanas, consulta ao 
dentista e internação hospitalar no último ano, filiação a plano médico de saúde e recomendação para a imunização contra rubéola, avaliada pela pergunta: "Você foi orientada por algum profissional de saúde sobre a importância de tomar a vacina contra rubéola?".

A associação entre as variáveis independentes e a vacinação referida foi verificada pelo teste qui-quadrado com nível de significância de 5\%. Foram calculadas as razões de prevalência (RP) brutas e IC95\%, e a análise ajustada foi conduzida por meio de regressão múltipla de Poisson com variância robusta 14 . A idade (contínua) foi utilizada como variável de ajuste para controlar possíveis diferenças da estrutura etária, considerando-se que as mulheres com idades mais avançadas foram menos expostas a campanhas e à rotina de vacinação contra a rubéola; no entanto, não foram observadas diferenças em relação às prevalências brutas estimadas.

No modelo múltiplo foram consideradas as variáveis que tiveram um valor de $\mathrm{p}<0,20$ na análise simples e a variável permaneceu no modelo se $\mathrm{p}<0,05$. As análises foram realizadas utilizando-se o programa Stata 11.0 (Stata Corp., College Station, Estados Unidos), cujos procedimentos para análise de inquéritos populacionais incorporam os aspectos da amostragem complexa.

O projeto de pesquisa foi aprovado pelo Comitê de Ética da UNICAMP, parecer no 079/2007.

\section{Resultados}

Das 868 mulheres com idades entre 10 e 49 anos que responderam às questões sobre a vacinação contra rubéola, $623(75,9 \%)$ relataram a imunização em algum momento na vida, 155 (14,7\%) afirmaram nunca ter recebido a vacina e $90(9,4 \%)$ não souberam informar ou não responderam à questão. Portanto, para as análises realizadas no presente estudo, a amostra foi composta pelas 778 mulheres com respostas válidas (sim ou não) para vacinação contra rubéola. A idade média da população estudada foi de 29,4 anos (IC95\%: 28,4-30,5).

A prevalência de vacinação referida (sim ou não) foi de 83,8\% (IC95\%: 79,6-88,0). Em relação aos motivos da não adesão à vacina contra rubéola, quase metade das mulheres $(48,5 \%)$ alegou a falta de orientação de profissional da área da saúde, 18,9\% referiram não considerar a vacina necessária, $10,1 \%$ relataram não ter idade suficiente para receber a vacina e $12,6 \%$ tiveram a doença previamente. Os demais motivos mencionados $(9,9 \%)$ incluem esquecimento, preguiça, medo, gravidez e falta de tempo.
Em relação ao local onde foi realizado o procedimento preventivo, 97,7\% (IC95\%: 96,2-99,1) das entrevistadas referiram o serviço público. Entre as que utilizaram o serviço privado, cerca de $30 \%$ relataram preferência pelo mesmo e os demais motivos referidos foram: ter convênio particular, ser ofertada no local de trabalho (empresa) e facilidade de acesso ao imunobiológico com seu "médico de confiança". Não houve relato de falta de vacina no sistema público ou inflexibilidade de horário do sistema de saúde.

Dentre as variáveis demográficas e socioeconômicas analisadas neste estudo, faixa etária, número de filhos e renda familiar per capita estiveram associados à vacinação contra rubéola e a escolaridade esteve no limite da significância estatística na análise simples. Maiores prevalências estatisticamente significativas de vacinação foram observadas entre as mulheres de 20 a 39 anos, nas que referiram um filho e naquelas com renda superior a três salários mínimos (Tabela 1).

A Tabela 2 apresenta a prevalência de vacinação, segundo condições de saúde e características relacionadas ao uso de serviços de saúde entre as mulheres em idade reprodutiva. A prevalência de vacinação entre as mulheres que receberam orientação de um profissional de saúde sobre a importância da vacina foi significativamente maior do que entre aquelas que não tiveram qualquer recomendação para a realização do procedimento preventivo $(\mathrm{RP}=2,14$; IC95\%: 1,63-2,81).

Os resultados da análise múltipla de regressão de Poisson são apresentados na Tabela 3. Faixa etária (30 a 39 anos), renda familiar per capita superior a três salários mínimos e a orientação de profissional de saúde sobre a vacina, estiveram positivamente associadas à vacinação contra a rubéola. A adesão ao imunobiológico foi cerca de duas vezes maior entre as mulheres que receberam orientação de profissional de saúde sobre este procedimento preventivo $(\mathrm{RP}=2,06$; IC95\%: 1,64-2,60).

\section{Discussão}

Os resultados deste estudo mostraram prevalência de vacinação de 83,8\% (IC95\%: 79,6-88,0) entre as mulheres em idade reprodutiva, residentes no Município de Campinas, sendo maior entre aquelas na faixa etária de 30 a 39 anos, com renda mensal per capita superior a três salários mínimos, e nas que referiram orientação de algum profissional de saúde sobre a importância de tomar a vacina.

Observou-se que mesmo entre os segmentos com maior adesão à vacina, a meta de $95 \%$ não 
Prevalência de vacinação contra rubéola em mulheres em idade reprodutiva, segundo variáveis demográficas e socioeconômicas. ISA-Camp 2008/2009, Campinas, São Paulo, Brasil.

\begin{tabular}{|c|c|c|c|c|}
\hline Variáveis & $\mathbf{n}$ & $\begin{array}{l}\text { Prevalência } \\
\text { (IC95\%) }\end{array}$ & Valor de $p$ * & $\begin{array}{c}\text { RP } \\
\text { (IC95\%) }\end{array}$ \\
\hline Faixa etária (anos) & & & $<0,01$ & \\
\hline $10-19$ & 406 & $75,1(65,3-82,8)$ & & 1,00 \\
\hline $20-29$ & 139 & $91,4(85,0-95,2)$ & & $1,22(1,08-1,36)$ \\
\hline $30-39$ & 120 & $91,7(84,9-95,5)$ & & $1,22(1,07-1,39)$ \\
\hline $40-49$ & 113 & $73,8(64,2-81,6)$ & & $0,98(0,86-1,10)$ \\
\hline Situação conjugal & & & 0,66 & \\
\hline Com cônjuge & 249 & $84,4(79,1-88,5)$ & & 1,00 \\
\hline Sem cônjuge & 529 & $83,2(77,2-87,9)$ & & $0,99(0,92-1,05)$ \\
\hline Cor da pele/raça & & & 0,24 & \\
\hline Branca & 537 & $84,9(80,3-88,7)$ & & 1,00 \\
\hline Não branca & 239 & $81,0(72,7-87,2)$ & & $0,95(0,87-1,04)$ \\
\hline Escolaridade (anos) & & & 0,06 & \\
\hline$\leq 4$ & 113 & $74,5(59,0-85,6)$ & & 1,00 \\
\hline $5-7$ & 195 & $81,2(73,5-87,0)$ & & $1,09(0,91-1,30)$ \\
\hline 8-11 & 335 & $84,4(78,2-89,0)$ & & $1,13(0,94-1,37)$ \\
\hline$\geq 11$ & 135 & $89,0(83,3-92,9)$ & & $1,19(0,98-1,45)$ \\
\hline Número de filhos & & & $<0,01$ & \\
\hline Nenhum & 497 & $82,4(75,7-87,5)$ & & 1,00 \\
\hline 1 & 114 & $93,9(86,0-97,5)$ & & $1,14(1,06-1,22)$ \\
\hline 2 ou mais & 167 & $79,7(74,1-84,4)$ & & $0,97(0,90-1,05)$ \\
\hline Renda mensal per capita (salários mínimos) ** & & & $<0,01$ & \\
\hline$\leq 1$ & 445 & $79,8(73,1-85,2)$ & & 1,00 \\
\hline $1-3$ & 229 & $84,8(78,7-89,4)$ & & $1,06(0,98-1,15)$ \\
\hline$>3$ & 104 & $93,0(86,6-96,5)$ & & $1,17(1,06-1,28)$ \\
\hline Atividade ocupacional & & & 0,08 & \\
\hline Sim & 302 & $86,3(81,5-90,0)$ & & 1,00 \\
\hline Não & 476 & $80,8(73,7-86,3)$ & & $0,94(0,87-1,01)$ \\
\hline
\end{tabular}

IC95\%: intervalo de 95\% de confiança; n: número de indivíduos na amostra não ponderada; RP: razão de prevalência.

* Valor de $p$ do teste qui-quadrado;

** Salário mínimo vigente à época da pesquisa: janeiro a abril/2008 = R\$ 415,00; maio/2008 a abril/2009=R\$450,00.

Nota: somente informações válidas foram incluídas na análise.

foi atingida, senão entre as que relataram a recomendação de algum profissional de saúde. Estudo sobre a população não vacinada em coortes de mulheres de 16 a 40 anos em 2007, revelou coberturas maiores de 95\% em faixas etárias de 16 a 25 anos no Estado de São Paulo, decrescendo a vacinação entre mulheres com maior idade 15 . Para diminuir a ocorrência de casos e manter um nível elevado de imunidade na população, são necessárias coberturas iguais ou superiores a $95 \% 6,16$.

A vacina é a forma mais eficaz de prevenir a ocorrência da doença na população, podendo ser indicada na rotina do atendimento na rede básica de saúde, em bloqueio vacinal e/ou em campanhas de vacinação. Este estudo avaliou a vacinação contra rubéola em algum momento da vida, mesmo assim, observou-se que parte das mulheres não vacinadas não se referiu à vacinação (prévia) no puerpério, tampouco à oferta da vacina na rotina dos serviços, atendose somente à campanha. Parte dessas mulheres alegou ainda que tinha "idade insuficiente" para ser vacinada, revelando falta de informação e desconhecimento sobre a oferta da vacina além das campanhas.

A falta de informação sobre o estado vacinal em 9,4\% (IC95\%: 6,7-12,2) das entrevistadas 
Prevalência de vacinação contra rubéola, segundo comportamentos relacionados à saúde, condições de saúde e características relacionadas ao uso de serviços de saúde em mulheres de 10 a 49 anos. ISA-Camp 2008/2009, Campinas, São Paulo, Brasil.

\begin{tabular}{|c|c|c|c|c|}
\hline Variáveis & $\mathrm{n}$ & $\begin{array}{l}\text { Prevalência } \\
\text { (IC95\%) }\end{array}$ & Valor de $p$ * & $\begin{array}{c}\text { RP } \\
\text { (IC95\%) }\end{array}$ \\
\hline Tabagismo & & & 0,56 & \\
\hline Não fumante & 63 & $83,5(78,3-87,6)$ & & 1,00 \\
\hline Fumante & 715 & $86,2(76,5-92,3)$ & & $0,97(0,87-1,07)$ \\
\hline Índice de massa corporal (kg/m²) & & & 0,94 & \\
\hline$<25$ & 537 & $84,1(78,3-88,5)$ & & 1,00 \\
\hline $25-30$ & 123 & $83,9(74,7-90,1)$ & & $1,00(0,90-1,11)$ \\
\hline$>30$ & 118 & $82,6(72,5-89,5)$ & & $0,98(0,88-1,09)$ \\
\hline Prática de atividade física & & & 0,34 & \\
\hline Não & 462 & $82,9(77,6-87,1)$ & & 1,00 \\
\hline Sim & 316 & $85,8(79,2-90,6)$ & & $1,04(0,96-1,11)$ \\
\hline Número de doenças crônicas & & & 0,47 & \\
\hline Nenhuma & 568 & $84,7(79,9-88,7)$ & & 1,00 \\
\hline Uma ou mais & 206 & $81,2(74,1-87,6)$ & & $0,96(0,87-1,07)$ \\
\hline Morbidade nos últimos 15 dias & & & 0,77 & \\
\hline Não & 618 & $84,1(79,4-87,8)$ & & 1,00 \\
\hline $\operatorname{Sim}$ & 160 & $82,8(72,1-89,9)$ & & $0,98(0,89-1,10)$ \\
\hline Hipertensão arterial & & & 0,07 & \\
\hline Não & 730 & $84,9(80,1-88,7)$ & & 1,00 \\
\hline Sim & 47 & $72,9(55,9-85,1)$ & & $0,86(0,70-1,06)$ \\
\hline Procura de serviço ou profissional para & & & 0,58 & \\
\hline \multicolumn{5}{|l|}{ problemas de saúde nos últimos 15 dias } \\
\hline Não & 624 & $84,2(79,2-88,2)$ & & 1,00 \\
\hline Sim & 154 & $82,3(74,0-88,3)$ & & $0,98(0,90-1,06)$ \\
\hline Consulta odontológica nos últimos 12 meses & & & 0,11 & \\
\hline Não & 299 & $80,4(72,9-86,3)$ & & 1,00 \\
\hline $\operatorname{Sim}$ & 479 & $85,9(80,9-89,7)$ & & $1,07(0,98-1,16)$ \\
\hline Internação hospitalar no último ano & & & 0,68 & \\
\hline Não & 706 & $84,0(78,9-88,1)$ & & 1,00 \\
\hline Sim & 72 & $81,7(68,8-90,0)$ & & $0,97(0,84-1,12)$ \\
\hline Plano médico de saúde & & & 0,06 & \\
\hline Não & 480 & $80,7(73,7-86,2)$ & & 1,00 \\
\hline Sim & 298 & $87,9(83,0-91,6)$ & & $0,92(0,84-1,01)$ \\
\hline Orientação sobre a vacinação & & & $<0,01$ & \\
\hline Não & 187 & $44,4(32,7-56,8)$ & & 1,00 \\
\hline Sim & 536 & $95,0(92,2-96,7)$ & & $2,14(1,63-2,81)$ \\
\hline
\end{tabular}

IC95\%: intervalo de 95\% de confiança; n: número de indivíduos na amostra não ponderada; RP: razão de prevalência.

* Valor de p do teste qui-quadrado.

reforça a necessidade de orientação pelas equipes de saúde antes e durante a imunização, sobre qual imunobiológico está sendo oferecido e seus benefícios. Os resultados mostram a baixa valorização do acesso a esse imunobiológico, frequentemente confundido com vacinas de outras composições.
De acordo com Moraes \& Ribeiro 13, segmentos populacionais com menor nível cultural e socioeconômico estão associados às menores coberturas vacinais. Estudos apontam maior cobertura vacinal contra sarampo, caxumba e rubéola em crianças de famílias com maior renda $17,18,19$. Aspectos culturais e étnicos também 
Modelo de regressão multivariada de Poisson para vacinação contra rubéola em mulheres de 10 a 49 anos. ISA-Camp 2008/2009, Campinas, São Paulo, Brasil.

\begin{tabular}{lccc}
\hline Variáveis & RP * (IC95\%) & Valore de $\mathbf{p}$ & Erro-padrão \\
\hline $\begin{array}{l}\text { Faixa etária (anos) } \\
\text { 10-19 }\end{array}$ & 1,00 & & \\
$20-29$ & $1,08(0,98-1,19)$ & 0,105 & 0,051 \\
$30-39$ & $1,13(1,02-1,25)$ & 0,021 & 0,058 \\
$40-49$ & $0,96(0,85-1,08)$ & 0,479 & 0,058 \\
Renda mensal per capita (salários mínimos) ** & & & \\
$\leq 1$ & 1,00 & 0,219 & 0,039 \\
1 1-3 & $1,05(0,97-1,13)$ & 0,005 & 0,037 \\
$>3$ & $1,10(1,03-1,18)$ & & \\
Orientação sobre a vacinação & & $<, 001$ & 0,241 \\
Não & 1,00 & & \\
Sim & $2,06(1,64-2,60)$ & & \\
\hline
\end{tabular}

IC95\%: intervalo de 95\% de confiança; RP: razão de prevalência.

* RP ajustada por meio de regressão múltipla de Poisson (723 mulheres foram incluídas no modelo final);

** Salário mínimo vigente à época da pesquisa: janeiro a abril/2008 = R\$ 415,00; maio/2008 a abril/2009=R\$450,00.

estiveram associados a diferenças de coberturas vacinais contra sarampo, caxumba e rubéola em crianças, em países europeus 20,21.

Como todas as vacinas de vírus atenuado, a da rubéola é contraindicada durante a gestação pelo risco teórico de causar danos ao feto, embora nunca se tenha registrado efeitos teratogêni$\cos 22$, ou em qualquer situação de imunossupressão ou alergia a componentes da vacina. Nas pessoas com imunodeficiências deve-se avaliar o risco/benefício individual 3,23. Essas, porém, são situações clínicas particulares e de baixa prevalência, difíceis de apreender em um inquérito de base populacional. Assim, a contraindicação formal ao imunobiológico não pode ser considerada causa de menor adesão à vacina. Chamou a atenção a menor prevalência/cobertura de vacinação entre mulheres que tiveram dois ou mais filhos em relação às uníparas na análise simples. Embora possa existir um viés de idade materna, isto é, são coortes de mulheres mais velhas (com menor exposição a campanhas e à rotina), essa informação indica que não foi fornecida a vacina após a primeira gestação, o que sugere uma oportunidade perdida de vacinação à população de risco, considerada estratégica para a eliminação da síndrome da rubéola congênita.

A solicitação de exame laboratorial para determinar os títulos de imunoglobulina G para o vírus da rubéola na primeira consulta pré-natal, permite avaliar a imunidade à rubéola e determinar a necessidade de imunização pós-parto, sendo esta, a estratégia de triagem mais comum nos países desenvolvidos 24. Destaca-se que a vacina não está contraindicada para mulheres em aleitamento materno, sendo o puerpério um período oportuno para a imunização ?.

Um dos achados mais relevantes deste estudo é a associação da vacinação com orientações de profissionais da área da saúde, cuja indicação ativa da vacina e de seus benefícios pode ter impacto decisivo no êxito da elevação das coberturas. Alguns autores já identificaram a relevância do aconselhamento e orientações de equipes de saúde para aumentar a adesão à vacinação, não somente contra a rubéola 25,26 .

Dentre as limitações do presente trabalho, deve-se considerar que a informação sobre a vacinação foi autorreferida, já que a confirmação por meio de registro no cartão de vacinação foi possível para apenas 7,3\% das mulheres entrevistadas. No Município de Campinas, no ano de 2008, a cobertura com a vacina tríplice viral foi de 92,4\% e a cobertura alcançada na Campanha de Vacinação contra Rubéola foi de 101,6\%. De acordo com os dados obtidos no Programa Nacional de Imunização (PNI. http://pni.datasus.gov. br/consulta_rubeola_mun_08_det.asp?UF=35, acessado em 10/Set/2012), para essa campanha, as coberturas foram de $115,1 \%$ e $87,4 \%$ para a população feminina nas faixas etárias de 20 a 29 anos e de 30 a 39, respectivamente. A cobertura é calculada pelo número de doses aplicadas na população-alvo, que é estimada para os anos 
intercensitários. O subdimensionamento de uma população específica, por erros nas estimativas, é um dos fatores que pode levar à observação de coberturas superestimadas (acima de 100\%). Em relação às mulheres mais jovens, a prevalência de vacinação estimada pelo inquérito esteve abaixo (91,4; IC95\%: 85,0-95,2) e entre as de 30 a 39 anos foi semelhante (91,7; IC95\%: 84,9-95,5) àquela registrada pelo Sistema de Vigilância Epidemiológica (SVE) do município. Destaca-se que o ISA-Camp foi uma pesquisa abrangente que avaliou várias dimensões da saúde e não especificamente a investigação da imunização. Ressalta-se que ainda não existem estudos que validem a informação sobre a vacinação referida por adultos, especificamente contra a rubéola ou tríplice ou dupla viral.

Os resultados deste estudo mostram uma boa cobertura da vacina contra rubéola na população estudada, porém abaixo de percentual recomendado para a eliminação da síndrome da rubéola congênita (95\%). Observou-se ainda heterogeneidade na vacinação referida entre os subgrupos estudados, de acordo com a faixa etária, renda e principalmente a indicação por profissional de saúde. O presente trabalho revelou que valores médios elevados podem ocultar segmentos populacionais com baixa cobertura, comprometendo o controle da doença. O Sistema Único de Saúde (SUS) é o principal disseminador da vacina. Nesse sentido, deve-se ressaltar que estratégias específicas para a divulgação da vacina e o maior envolvimento dos profissionais de saúde, oferecendo informações e esclarecimentos à população sobre os riscos da síndrome da rubéola congênita, principalmente entre as mulheres não vacinadas e em idade fértil, podem contribuir significativamente para que grupos em situações de maior vulnerabilidade sejam atingidos.

Os dados deste inquérito apresentaram resultados inéditos no Brasil sobre a prevalência da vacinação contra rubéola em mulheres de 10 a 49 anos e sua associação com fatores demográficos, socioeconômicos, comportamentos relacionados à saúde, condições de saúde e uso de serviços. Este estudo revelou que a recomendação por parte do profissional de saúde é essencial para a adesão a esse procedimento preventivo.

A vacinação é uma intervenção de caráter preventivo, disponível ao usuário na medida em que este a considere uma necessidade de saúde, com subsequente decisão de buscá-la nos serviços 13 . Por isso, o desenvolvimento de estratégias que contribuam para melhorar o conhecimento das mulheres e da população sobre a importância da vacina e seus benefícios, pode elevar as coberturas em grupos mais vulneráveis, principalmente em períodos entre as campanhas de vacinação, visando à erradicação da rubéola e da síndrome da rubéola congênita no país.

\section{Resumen}

Las mujeres en edad reproductiva son la población de mayor interés para la prevención del síndrome de la rubeola congénita. El objetivo del trabajo fue evaluar la prevalencia de vacunación contra la rubeola en mujeres e identificar factores asociados y motivos de la no adhesión al programa de vacunación. Se trata de un estudio transversal de base poblacional, realizado en Campinas, São Paulo, Brasil, en 2008/2009, con una muestra por conglomerados y en dos fases. De las 778 mujeres, de 10 a 49 años, un 83,8\% (IC95\%: 79,6-88,0) informaron de vacunación en algún momento de la vida. La franja de edad (30-39 años), renta familiar per cápita superior a tres salarios mínimos y la orien- tación de un profesional de salud estuvieron positivamente asociadas a la vacunación contra la rubeola. Los principales motivos de la no adhesión fueron la falta de orientación del profesional de salud sobre su importancia $(48,5 \%)$ y no considerarla necesaria (18,9\%). La recomendación del profesional de salud fue el factor más fuertemente asociado a la adhesión de las mujeres a la vacunación. En este sentido, su indicación por los equipos de salud puede ampliar el conocimiento sobre su importancia y sus beneficios.

Síndrome de Rubéola Congénita; Vacuna contra la Rubéola; Vacunación; Salud de la Mujer 


\section{Colaboradores}

P. M. S. B. Francisco realizou a proposta do artigo, revisão da literatura, análise dos dados e redação do texto. C. Senicato colaborou na proposta do artigo, revisão da literatura e redação do texto. M. R. Donalisio contribuiu na redação do texto, na revisão da literatura e do manuscrito. M. B. A. Barros realizou a revisão do manuscrito.

\section{Agradecimentos}

Ao CNPq processo no 409747/2006-8) pelo financiamento da pesquisa e pela bolsa de produtividade de M. B. A. Barros e M. R. Donalisio, e ao Ministério da Saúde e à Secretaria de Saúde de Campinas pelo apoio financeiro para a realização do inquérito (parceria UNICAMP/FUNCAMP/SMS no. 4300). À Fundação de Amparo à Pesquisa do Estado de São Paulo (FAPESP) pela bolsa de pós-doutorado de P. M. S. B. Francisco e pela bolsa de doutorado de C. Senicato.

\section{Referências}

1. Bloom S, Rguig A, Berraho A, Zniber L, Bouazzaoui $\mathrm{N}$, Zaghloul $\mathrm{K}$, et al. Congenital rubella syndrome burden in Morocco: a rapid retrospective assessment. Lancet 2005; 365:135-41.

2. Department of Immunization, Vaccines and Biologicals, World Health Organization. WHO vaccinepreventable diseases: monitoring system. 2007 global summary. Geneva: World Health Organization; 2008

3. Departamento de Vigilância Epidemiológica, Secretaria de Vigilância em Saúde, Ministério da Saúde. Brasil livre de rubéola. Campanha nacional de vacinação para eliminação da rubéola: relatório. Brasília: Ministério da Saúde; 2009.

4. Cutts FT, Vynnycky E. Modelling the incidence of congenital rubella syndrome in developing countries. Int J Epidemiol 1999; 28:117684.

5. Hinman AR, Irons B, Lewis M, Kandola K. Economic analyses of rubella and rubella vaccines: a global review. Bull World Health Organ 2002; 80:264-70.

6. Departamento de Vigilância Epidemiológica, Secretaria de Vigilância em Saúde, Ministério da Saúde. Rubéola. In: Departamento de Vigilância Epidemiológica, Secretaria de Vigilância em Saúde, Ministério da Saúde, organizador. Guia de vigilância epidemiológica. 7ạ Ed. Brasília: Ministério da Saúde; 2009. p. 1-17. (Série A. Normas e Manuais Técnicos).
7. Departamento de Vigilância Epidemiológica, Secretaria de Vigilância em Saúde, Ministério da Saúde. Campanha Nacional de Vacinação contra Rubéola para eliminação da rubéola e da síndrome da rubéola congênita no Brasil. Brasília: Ministério da Saúde; 2008. (Informe Técnico, 1).

8. Pan American Health Organization. Public health burden of rubella and CRS. EPI Newsl 1998; 20:2-3.

9. Castillo-Solórzano C, Marsigli C, Bravo-Alcántara P, Flannery B, Ruiz Matus C, Tambini G, et al. Elimination of rubella and congenital rubella syndrome in the Americas. J Infect Dis 2011; 204 Suppl 2:S571-8.

10. Santos ED. Avaliação do impacto das estratégias e prevenção e controle da rubéola e da síndrome da rubéola congênita nos estados de São Paulo, Paraná, Rio Grande do Norte, Goiás e Pará, 1992-2003 [Dissertação de Mestrado]. Rio de Janeiro: Escola Nacional de Saúde Pública Sergio Arouca, Fundação Oswaldo Cruz; 2005.

11. Departamento de Vigilância Epidemiológica, Secretaria de Vigilância em Saúde, Ministério da Saúde. Plano de ação: campanha nacional de vacinação para eliminação da rubéola no Brasil. Brasília: Ministério da Saúde; 2008. 
12. Department Imunization, Vaccines and Biologicals, World Health Organization. Report of a meeting on preventing congenital rubella syndrome: immunization strategies, surveillance needs. Geneva: World Health Organization; 2000.

13. Moraes JC, Ribeiro MCSA. Desigualdades sociais e cobertura vacinal: uso de inquéritos domiciliares. Rev Bras Epidemiol 2008; 11 Suppl 1:S113-24.

14. Barros AJ, Hirakata VN. Alternatives for logistic regression in cross-sectional studies: an empirical comparison of models that directly estimate the prevalence ratio. BMC Med Res Methodol 2003; 3:21.

15. Segatto C, Samad S, Mengue SS, Rodrigues G, Flannery B, Toscano CM. Historical analysis of birth cohorts not vaccinated against rubella prior to national rubella vaccination campaign, Brazil. J Infect Dis 2011; 204 Suppl 2:S608-15.

16. Anderson RM, May RM. Infectious diseases of humans: dynamics and control. $5^{\text {th }}$ Ed. Oxford: Oxford University Press; 1991.

17. Pearce A, Law C, Elliman D, Cole TJ, Bedford H. Factors associated with uptake of measles, mumps, and rubella vaccine (MMR) and use of single antigen vaccines in a contemporary UK cohort: prospective cohort study. BMJ 2008; 336:754-7.

18. Smith A, Yarwood J, Salisbury D. Tracking mothers' attitudes to MMR immunization 1996-2006. Vaccine 2007; 25:3996-4002.

19. Roberts KA, Dixon-Woods M, Fitzpatrick R, Abrams KR, Jones DR. Factors affecting uptake of childhood immunization: a Bayesian synthesis of qualitative and quantitative evidence. Lancet 2002; 360:1596-9.
20. Simpson L, Owens P, Zodet M, Chevarley F, Dougherty D, Elixhauser A, et al. Health care for children and youth in the United States: annual report on patterns of coverage, utilization, quality and expenditures by income. Ambul Pediatr 2005; 5:6-44.

21. Mixer RE, Jamrozik K, Newsom D. Ethnicity as a correlate of the uptake of the first dose of mumps, measles and rubella vaccine. J Epidemiol Community Health 2007; 61:797-801.

22. Bar-Oz B, Levicheck Z, Moretti ME, Mah C, Andreou S, Koren G. Pregnancy outcome following rubella vaccination: a prospective controlled study. Am J Med Gen 2004; 130:52-4.

23. Departamento de Vigilância Epidemiológica, Secretaria de Vigilância em Saúde, Ministério da Saúde. Manual de vigilância epidemiológica de eventos adversos pós-vacinação. 2a Ed. Brasília: Ministério da Saúde; 2007. (Série A. Manual e Normas Técnicas em Saúde).

24. Schrag SJ, Arnold KE, Mohle-Boetani JC, Lynfield R, Zell ERM, Karen RN, et al. Prenatal screening for infectious diseases and opportunities for prevention. Obstet Gynecol 2003; 102:753-60.

25. Vieira JC, Carvalho MTB, Checchia RL, Trombiere M, Flannery B. Survey of rubella knowledge and acceptability of rubella vaccination among Brazilian adults prior to mass vaccination. Rev Panam Salud Pública 2011; 30:335-41.

26. Francisco PMBS, Barros MBA, Donalisio MR. Vacinação contra influenza em idosos: prevalência, fatores associados e motivos da não-adesão em Campinas, São Paulo, Brasil. Cad Saúde Pública 2011; 27:417-26.

Recebido em 03/Jul/2012

Versão final reapresentada em 14/Set/2012

Aprovado em 09/Out/2012 